\title{
Non-Lethal Levels of Oxidative Stress in Response to Short-Term Intermittent Hypoxia Enhance $\mathrm{Ca}^{2+}$ Handling in Neonatal Rat Cardiomyocytes
}

\author{
Tsung-I Chen ${ }^{a}$ Yu-Cheng Hsu ${ }^{b}$ Chih-Feng Lien ${ }^{c}$ Jian-Hong Lin ${ }^{d}$ Hung-Wen Chiue \\ Kun-Ta Yang b,c,e,f
}

aCenter of Physical Education, Office of General and Basic Education, Tzu Chi University, bPhysiological and Anatomical Medicine, School of Medicine, Tzu Chi University, Institute of Medical Sciences, College of Medicine, Tzu Chi University, ${ }^{\mathrm{P}} \mathrm{PhD}$ program in Pharmacology and Toxicology, Tzu Chi University, eMaster program, Physiology and Anatomical Medicine, School of Medicine, Tzu Chi University, ${ }^{\text {}}$ Department of Physiology, College of Medicine, Tzu Chi University, Hualien, Taiwan

\section{Key Words}

Intermittent hypoxia $\cdot$ Reactive oxygen species - Calcium regulation $\cdot$ Sarcoplasmic reticulum $\mathrm{Ca}^{2+}$ ATPase $\cdot$ Sodium calcium exchanger $\bullet$ Protein kinase $\mathrm{C}$

\begin{abstract}
Background/Aims: Intermittent hypoxia $(\mathrm{IH})$ may exert pre-conditioning-like cardioprotective effects and alter $\mathrm{Ca}^{2+}$ regulation; however, the exact mechanism of these effects remains unclear. Thus, we examined $\mathrm{Ca}^{2+}$-handling mechanisms induced by $\mathrm{IH}$ in rat neonatal cardiomyocytes. Methods: Cardiomyocytes were exposed to repetitive hypoxia-re-oxygenation cycles for 1-4 days. Mitochondrial reactive oxygen species (ROS) generation was determined by flow cytometry, and intracellular $\mathrm{Ca}^{2+}$ concentrations were measured using a live-cell fluorescence imaging system. Protein kinase $\mathrm{C}(\mathrm{PKC})$ isoforms and $\mathrm{Ca}^{2+}$-handling proteins were analysed using immunofluorescence and western blotting. Results: After IH exposure for 4 days, the rate of $\mathrm{Ca}^{2+}$ extrusion from the cytosol to the extracellular milieu during $40-\mathrm{mM} \mathrm{KCl}$-induced $\mathrm{Ca}^{2+}$ mobilization increased significantly, whereas ROS levels increased mildly. IH activated PKC isoforms, which translocated to the membrane from the cytosol, and $\mathrm{Na}^{+} / \mathrm{Ca}^{2+}$ exchanger- 1 , leading to enhanced $\mathrm{Ca}^{2+}$ efflux capacity. Simultaneously, IH increased sarcoplasmic reticulum (SR) $\mathrm{Ca}^{2+}$-ATPase and ryanodine receptor 2 (RyR-2) activities and RyR-2 expression, resulting in improved $\mathrm{Ca}^{2+}$ uptake and release capacity of SR in cardiomyocytes. Conclusions: $\mathrm{IH}-$ induced mild elevations in ROS generation can enhance $\mathrm{Ca}^{2+}$ efflux from the cytosol to the extracellular milieu and $\mathrm{Ca}^{2+}$-mediated $\mathrm{SR}$ regulation in cardiomyocytes, resulting in enhanced $\mathrm{Ca}^{2+}$-handling ability.
\end{abstract}

Copyright $\odot 2014$ S. Karger AG, Basel 
Chen et al.: Intermittent Hypoxia Alters $\mathrm{Ca}^{2+}$ Homeostasis in Cardiomyocytes

\section{Introduction}

Intermittent hypoxia $(\mathrm{IH})$ occurs frequently under many physiological conditions, such as strenuous exercise and sojourns at high altitude, as well as pathophysiological conditions, such as asthma and obstructive sleep apnoea [1-3]. IH is characterized as cyclic episodes of hypoxia of short duration followed by normoxia [4], leading to increased generation of intracellular reactive oxygen species (ROS) during re-oxygenation following hypoxia [5]. Previously, excess ROS accumulation was itself considered injurious because it can cause lipid peroxidation, protein oxidation, DNA damage [6] and intracellular ion deregulation [7], damaging cellular physiological function. However, it is generally accepted at present that ROS may exert beneficial actions [8] because short or moderate durations of ROS generation can result in pre-conditioning protection of the heart [9] against ischemia/reperfusion (I/R) injury [1]. This protective effect is partially due to IH-induced increases in antioxidative capacity for removing excess ROS [10] and improved $\mathrm{Ca}^{2+}$ handling for attenuating cytosolic $\mathrm{Ca}^{2+}$ overload [11].

$\mathrm{Ca}^{2+}$ is an intracellular signalling molecule that regulates many different cellular functions. In cardiomyocytes, $\mathrm{Ca}^{2+}$ homeostasis plays a crucial role in maintaining the normal cycles of cardiac contraction/relaxation under physiological conditions [12]. During contraction, $\mathrm{Ca}^{2+}$ enters the myocyte through L-type $\mathrm{Ca}^{2+}$ channels and induces $\mathrm{Ca}^{2+}$ release from the sarcoplasmic reticulum (SR) through the ryanodine receptor (RyR). During relaxation, $\mathrm{Ca}^{2+}$ is transported into SR via SR $\mathrm{Ca}^{2+}$-ATPase (SERCA) [13] and by $\mathrm{Ca}^{2+}$ extrusion via the $\mathrm{Na}^{+} / \mathrm{Ca}^{2+}$ exchanger (NCX) and other $\mathrm{Ca}^{2+}$ pumps [14]. Recently, there has been significant interest in improving the $\mathrm{Ca}^{2+}$-handling ability for the prevention of heart disease using non-pharmacological interventions, including ischemic pre-conditioning, exercise and IH. Ischemic pre-conditioning can exert cardioprotective effects by decreasing I/R injuryinduced $\mathrm{Ca}^{2+}$ overload $[11,15]$, as evidenced by the enhanced recovery of the myocardial contractile function and prevention of arrhythmias [16]. Regular moderate exercise training also results in beneficial heart adaptations by improving contractile capacity, which is associated with faster generation and decay of intracellular calcium transients [17]. In IH pre-conditioning, although the activity of RyR of SR and sarcolemmal NCX increased during $\mathrm{I} / \mathrm{R}$ in cardiomyocytes isolated from rats exposed to chronic IH, these IH-induced beneficial effects were not observed in the pre-I/R status [18]. In contrast, IH with severe hypoxia yields deleterious effects, causing increases in myocardium infarction during I/R [19]. Thus, the ROS levels induced by IH may influence the injurious or beneficial cardiovascular effects because mitochondria respond to graded hypoxia by increasing ROS generation [20]. Moreover, under physiological conditions, the effects of IH-induced ROS generation on $\mathrm{Ca}^{2+}$ handling remain unclear. Therefore, the aims of this study were to examine the level of ROS generation induced by short-term IH exposure and the mechanisms by which the generated ROS affect alteration in $\mathrm{Ca}^{2+}$ regulation mediated by the $\mathrm{Ca}^{2+}$-handling proteins NCX-1, SERCA-2 and RyR-2 under adaptation to IH in rat neonatal cardiomyocytes.

\section{Materials and Methods}

\section{Chemicals and solutions}

N-2-hydroxy-ethylpiperazine-N'-2-ethanesulphonic acid (HEPES)-buffered Tyrode solution consisted of $140 \mathrm{mM} \mathrm{NaCl}, 4.5 \mathrm{mM} \mathrm{KCl}, 1.0 \mathrm{mM} \mathrm{MgCl}, 2.0 \mathrm{mM} \mathrm{CaCl}_{2}, 11 \mathrm{mM}$ glucose, $10 \mathrm{mM}$ HEPES and $1.2 \mathrm{mM}$ $\mathrm{KH}_{2} \mathrm{PO}_{4}$, with $\mathrm{pH}$ adjusted to 7.4 at $37^{\circ} \mathrm{C}$ with $\mathrm{NaOH}$. $\mathrm{Ca}^{2+}$-free medium lacked $\mathrm{CaCl}_{2}$ and contained 0.5 $\mathrm{mM}$ ethyleneglycol-bis (beta-aminoethylether)- $\mathrm{N}, \mathrm{N}^{\prime}$-tetraacetic acid. For $\mathrm{Na}$-free medium, $\mathrm{Na}^{+}$ions were isotonically replaced with N-methyl-D-glucamine. All fluorescent indicators were purchased from Molecular Probes (Eugene, OR, USA). F-12 medium, foetal bovine serum (FBS), horse serum (HS), Hank's balanced salt solution and penicillin were purchased from Gibco/Life Technologies, USA). Anti-protein kinase C (alpha, beta, gamma) [PKC $(\alpha, \beta, \gamma)]$, anti-RyR-2, anti-SERCA-2, anti-NCX-1 and anti- $\beta$-actin monoclonal antibodies were obtained from Chemicon (USA). All other chemicals were purchased from Sigma (USA). 
Preparation of cultured ventricular myocytes

All procedures were performed in accordance with the Animal Care Guidelines of Tzu Chi University. Because male and female neonatal rats are not easily sexed visually, ventricles from multiple hearts are typically pooled, so neonatal rats cardiomyocytes preparations represent a mix cells from both males and females [21]. Two-day-old Sprague-Dawley rats were killed by cervical dislocation and decapitated, and ventricular myocyte cultures were prepared as described previously [22]. In brief, myocytes were dissociated from the ventricles through repeated digestion in $2 \mathrm{ml}$ of enzyme solution $(0.051 \%$ pancreatine and collagenase in Hank's buffer), followed by enzyme inactivation using an F-12 medium (80\% F-12 nutrient mixture, $10 \% \mathrm{FBS}, 10 \% \mathrm{HS}$ and $1 \%$ penicillin). Non-myocytes were removed when the cells were pre-plated for $1 \mathrm{~h}$ at $37^{\circ} \mathrm{C}$ in an incubator $\left(21 \% \mathrm{O}_{2}, 5 \% \mathrm{CO}_{2}\right)$. Ventricular myocytes were plated on $35-\mathrm{mm}$ collagen-coated cover slips in F-12 medium with $10 \mu \mathrm{M}$ cytosine arabinoside. The medium was replaced daily. All experiments were performed on day 1 after cardiomyocyte plating.

Intermittent hypoxia exposures

Ventricular myocytes were incubated in Plexiglas box chambers (length $25 \mathrm{~cm}$, width $30 \mathrm{~cm}$, height $15 \mathrm{~cm}$ ). The myocytes were exposed to normoxia (NOX; $21 \% \mathrm{O}_{2}, 5 \% \mathrm{CO}_{2}$ and balanced $\mathrm{N}_{2}$ ) or $\mathrm{IH}\left(5 \% \mathrm{O}_{2}, 5 \%\right.$ $\mathrm{CO}_{2}$ and balanced $\mathrm{N}_{2}$ for 30 min alternating with 30-min NOX), using a timed solenoid valve controlled for 1-4 days. Oxygen fractions in the chambers were continuously monitored by an oxygen detector. A micro dissolved oxygen electrode from Lazar Research Laboratories (DO-166MT-1) was used to detect fluctuation of oxygen concentrations in the medium and the chamber.

Measurement of intracellular $\mathrm{Ca}^{2+}$ concentrations $\left(\left[\mathrm{Ca}^{2+}\right]_{i}\right)$

Cells were loaded with $5 \mu \mathrm{M}$ Fluo-3 AM for $60 \mathrm{~min}$ at room temperature. Fluorescence was monitored with a fluorescent microscope (DMI3000B; Leica) using the excitation/emission wavelengths of 488/520 $\mathrm{nm}$, respectively. Signal increases are presented as the peak/basal fluorescence ratio.

\section{Measurement of membrane potentials}

The membrane potential-sensitive dye bis-(1,3-dibutylbarbituric acid) trimethine oxonol ( $\left.\operatorname{DiBAC}_{4(3)}\right)$ was used to measure membrane potentials as described previously [23]. Briefly, cardiomyocytes were incubated with HEPES-buffered Tyrode solution containing $100 \mathrm{nM} \mathrm{DiBAC}_{4(3)}\left(30 \mathrm{~min}, 37^{\circ} \mathrm{C}\right)$. $\mathrm{DiBAC}_{4(3)}$ is a bis-barbituric acid oxonol compound that partitions into the membrane as a function of membrane potential. Hyperpolarization causes extrusion of the dye and decreased fluorescence, whereas depolarization causes enhanced fluorescence. Fluorescence was monitored with a fluorescent microscope (DMI3000B; Leica) using the excitation/emission wavelengths of $490 / 516 \mathrm{~nm}$, respectively. $\mathrm{DiBAC}_{4(3)}$ was maintained at 100 $\mathrm{nM}$ in all solutions.

\section{Mitochondrial ROS measurements}

Cardiomyocytes were incubated with MitoSOX ${ }^{\mathrm{TM}}$ Red reagent $2.5 \mu \mathrm{M}$ for $30 \mathrm{~min}$ before harvesting. After a PBS wash, fluorescence was measured on a FACS Calibur Flow Cytometer (Becton Dickinson Biosciences, USA) using excitation/emission wavelengths of $510 / 580 \mathrm{~nm}$.

\section{Immunofluorescence staining of ventricular myocytes}

Cells were fixed with methanol at $4^{\circ} \mathrm{C}$ for $10 \mathrm{~min}$. After incubation for $5 \mathrm{~min}$ in $5 \%$ non-fat milk, the cells were reacted with primary antibody for $60 \mathrm{~min}$ at $37^{\circ} \mathrm{C}$, followed by secondary antibody (FITC-conjugated goat anti-rabbit IgG or anti-mouse IgG) for $60 \mathrm{~min}$ at $37^{\circ} \mathrm{C}$. Images were obtained by confocal microscopy (TCS-SPII; Leica) with resolution of $512 \times 512$ pixels. FITC represented green fluorescence with excitation/ emission wavelengths at $488 / 500-550 \mathrm{~nm}$.

\section{Analysis of nuclear areas}

Cells were observed using laser scanning confocal microscopy (TCS-SPII; Leica). Images were analysed using Leica confocal software to calculate the sizes of nuclei stained with Hoechst 33342 fluorochrome blue fluorescence with excitation/emission wavelengths at 340/450-500 nm. 
Flow cytometric analysis of cell death

Apoptosis/necrosis was determined by Annexin V-FITC Apoptosis Detection Kit (BioVision, Inc., Mountain View, $\mathrm{CA}$ ) according to the manufacturer's recommendations. After 4-day IH or $\mathrm{H}_{2} \mathrm{O}_{2}$ treatment for $30 \mathrm{~min}$ at $37^{\circ} \mathrm{C}$, cardiomyocytes were washed with NT, trypsinized, harvested, and stained with Annexin V-FITC and SYTOX green (BioVision, Inc., Mountain View, CA) in binding buffer for $10 \mathrm{~min}$ at room temperature. Fluorescence was measured on a FACSCalibur Flow Cytometer (Becton Dickinson Biosciences, USA) The excitation/emission wavelengths for Annexin V-FITC and SYTOX were 488/530 nm, respectively.

\section{Western blots}

Cells were lysed on ice with $200 \mu$ lof lysis buffer $\left(50 \mathrm{mM}\right.$ Tris- $\mathrm{HCl}, \mathrm{pH} 7.5,0.5 \mathrm{M} \mathrm{NaCl}, 5 \mathrm{mM} \mathrm{MgCl}{ }_{2}, 0.5 \%$ NP-40, $1 \mathrm{mM}$ PMSF, $1 \mathrm{~g} / \mathrm{ml}$ pepstatin and $50 \mathrm{~g} / \mathrm{ml}$ leupeptin) and centrifuged at $10,600 \times \mathrm{g}$ at $4^{\circ} \mathrm{C}$ for $10 \mathrm{~min}$. The protein concentrations in the supernatants were quantified using a BSA Protein Assay Kit. Electrophoresis was performed using an SDS-PAGE Bis-Tris Electrophoresis System using $30 \mu \mathrm{g}$ of reduced protein extract per lane. Resolved proteins were then transferred to PVDF membranes. Membranes were blocked with $5 \%$ non-fat milk for $1 \mathrm{~h}$ at RT and probed with appropriate dilutions of primary antibodies against $\beta$-actin, PKC $(\alpha, \beta, \gamma)$ and NCX-1 at $4^{\circ} \mathrm{C}$ overnight. After the PVDF membranes were washed three times with Tris buffered saline with $0.05 \%$ Tween-20 (0.05\% TTBS, $125 \mathrm{mM} \mathrm{NaCl,} 125 \mathrm{mM}$ Tris-HCl, 0.05\% Tween-20, pH 7.6) at RT, they were incubated with the appropriate secondary antibody (goat anti-mouse or anti-rabbit, 1:10,000) labelled with horseradish peroxidase for $1 \mathrm{~h}$ at RT and then washed three times with $0.05 \%$

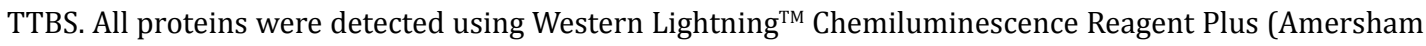
Biosciences, Arlington Heights, IL, USA). The signals were visualized by exposing the membranes to X-ray films (Kodak, USA). The resulting bands were captured with a scanner and quantified as arbitrary units (OD $\times$ band area) with ImageJ analysis software (National Institutes of Health, Bethesda, MD, USA).

Real-time quantitative polymerase chain reaction ( $q$-PCR)

RNA was extracted from cardiomyocytes using Trizol Reagent (Invitrogen, USA) and cDNA was synthesized using a Verso ${ }^{\mathrm{TM}}$ cDNA kit (Thermo, USA). Real-time qPCR was performed using an ABI 7300 Real Time PCR system (Life Technologies, USA) with $2 \times$ Maxima SYBR green qPCR Master Mix and ROX solution (Thermo, USA). The following primer pairs were used: NCX-1 [24] forward 5'-GTGTTTGTCGCTCTTGGAACCTC-3' and reverse 5'-CGTTGCTTCCGGTGACATTG -3' and RyR-2 forward 5'-AGAGAAGGAAGTGGCACGGAA-3' and reverse 5'-CCAGTAACTCGCTGATTCTGTCT-3' and SERCA-2 forward 5'-ATGAACCTGAAATGGGCAAG-3' and reverse 5'-GGAACTTTGTCACCAACAGCA-3' and Calsequestrin-2 [25] forward 5'- GGAGCATCAAAGACCCACCC - 3 ' and reverse 5'- TTCTCCGCAAATGCCACAAT - 3 ' and GAPDH forward 5'-TGCACCACCAACTGCTTAGC-3' and reverse 5'-GGCATGGACTGTGGTCATGAG-3'. Total RNA (3 $\mu \mathrm{g}$ ) was used to perform the reverse transcription reaction. A 1:10 dilution of the synthesized cDNA with RNasefree water (total volume $=25 \mu \mathrm{l}$ ) was subsequently used for qPCR. The comparative $C_{t}$ method $\left(2^{-\Delta \Delta C t}\right)$ was used to quantify gene expression, where $\Delta \Delta \mathrm{C}_{\mathrm{t}}=\Delta \mathrm{C}_{\mathrm{t}}$ (sample) $-\Delta \mathrm{C}_{\mathrm{t}}$ (reference).

\section{Statistics}

Statistical analyses were performed using SPSS 13.0 software (SPSS, Inc., Chicago, IL, USA). For fluorescence measurements and Western blot analyses, all results are expressed as means and standard errors of the means (mean \pm SEM). Statistical differences were compared using the t-test and one-way ANOVA with post-hoc test, taking a $p$ value of $<0.05$ as significant.

\section{Results}

IH profiles and IH-induced mitochondrial ROS generation in cardiomyocytes

IH profiles were recorded in the gas phase and medium in IH chambers, revealing the time lag in the development of hypoxia between the gas phase and medium. The nadir and peak oxygen fractions recorded in the gas phase were 5\% during hypoxia and $20 \%$ during normoxia, respectively (Fig. 1A). The nadir and peak dissolved oxygen recorded in the culture medium were $9 \%$ during hypoxia and 18\% during normoxia, respectively (Fig. 1B). In mitochondrial ROS measurements, the ROS levels were significantly increased by IH on 
Fig. 1. Intermittent hypoxia (IH) induced mitochondrial reactive oxygen species (ROS) generation in cardiomyocytes. Normoxia (NOX) and $\mathrm{IH}$ profiles recorded in the gas phase (A) and medium (B) in Plexiglas box chambers. Mitochondrial ROS generation was determined by flow cytometry using the mitochondrial superoxide probe MitoSOX Red (C). Quantification of the levels of mitochondrial ROS generation in cardiomyocytes exposed to NOX for 4 days (NOX4, $\mathrm{n}=5$ ), IH for 1-4 days (IH1-4, $\mathrm{n}=5-6$ for each group), IH4 plus 1,10-phenanthroline (IH4+Phen, $\mathrm{n}=3$ ) and $\mathrm{Mn}$ (III) tetrakis(4-benzoic acid)porphyrin (IH4+MnTBAP, $\mathrm{n}=3$ ) (D). ${ }^{* *} p<0.01$ compared to NOX4. ${ }^{\# \#} p<0.01$ compared to IH4. Values are presented as means \pm SEM.

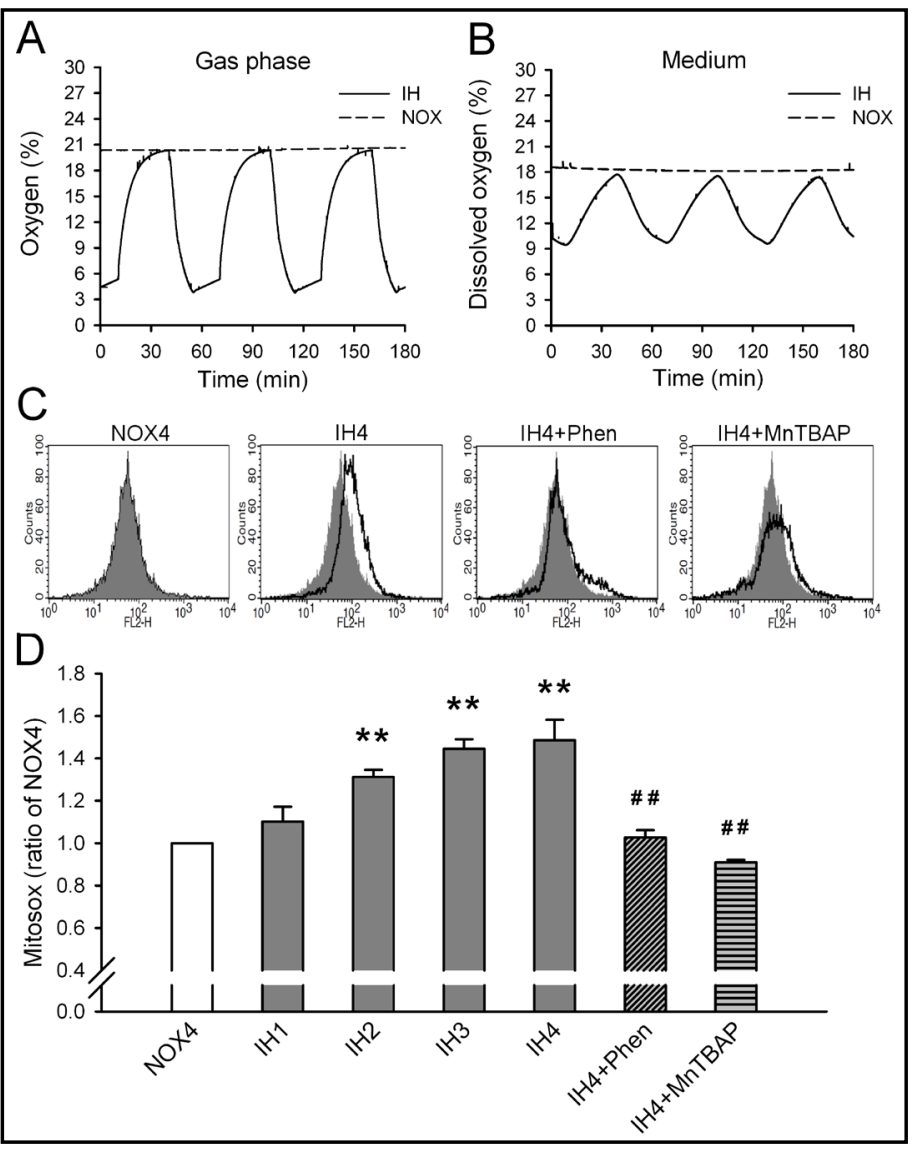

days 2-4 compared with normoxia (all $p<0.05$ ) (Fig. 1C and 1D). To further clarify whether the increased levels of mitochondrial ROS were induced by IH, $100 \mathrm{nM}$ 1,10-phenanthroline (Phen), an $\mathrm{Fe}^{2+}$ chelator that reduces $\mathrm{OH}$ generation by inhibiting Fenton reactions, was added daily to the culture medium for 4 days (IH4+Phen). Significantly lower $\mathrm{OH}^{\cdot}$ levels were observed in mitochondria for IH4+Phen than for IH4 $(p<0.05)$ (Fig. 1D), indicating that Phen could abolish increases in $\mathrm{OH}^{\cdot}$ generation induced by $\mathrm{IH} 4$, leading to reduced mitochondrial ROS generation $(p<0.05)$ (Fig. 1C and 1D). Moreover, Phen was replaced by Mn (III) tetrakis(4-benzoic acid)porphyrin (MnTBAP) chloride, an SOD mimic and a superoxide scavenger, to confirm whether IH induced increased levels of mitochondrial ROS generation in cardiomyocytes. Consistent with the addition of Phen to IH4, $100 \mu \mathrm{M}$ MnTBAP (IH4+MnTBAP) abolished mitochondrial ROS generation in 4-day IH-exposed cardiomyocytes $(p<0.05)$ (Fig. 1D). Therefore, our findings suggested that 4 days of IH exposure induced an increase in mitochondrial ROS generation in rat neonatal cardiomyocytes.

\section{IH induced non-lethal ROS levels in cardiomyocytes}

Cardiomyocyte death was quantified by condensation nuclei, a characteristic apoptotic feature, because condensed apoptotic nuclei have lower nuclear area values. Our results illustrated that the nuclear areas neither differed between the 1- to 4-day IH and NOX groups nor were there significant differences within any of the IH or NOX groups (Fig. 2A and 2B). To examine the levels of oxidative stress that caused nuclear condensation in cardiomyocytes, intracellular oxidative stress was induced in cardiomyocytes via exposure to various $\mathrm{H}_{2} \mathrm{O}_{2}$ concentrations for $1 \mathrm{~h}$. The nuclear areas were significantly decreased by 30,50 and $100 \mu \mathrm{M}$ $\mathrm{H}_{2} \mathrm{O}_{2}$ (all $p<0.05$ ) but not by $10 \mu \mathrm{M} \mathrm{H}_{2} \mathrm{O}_{2}$ compared with those in the control group ( $p>0.05$, Fig. 2B). To further confirm these results, we performed an Annexin $V$ assay for calculating the percentage of viable cells (M1), apoptotic fractions (M2) and necrotic fractions (M3). The percentage of apoptotic and necrotic cells did not differ between the NOX4 and IH4 groups 
Fig. 2. Intermittent hypoxia (IH) did not alter cell death in cardiomyocytes. The nuclear area was examined using Hoechst 33342 fluorochrome staining and imaged by confocal microscopy (A). The nuclear area (blue) in cardiomyocytes exposed to normoxia (NOX) and $\mathrm{IH}$ for 1-4 days and various concentrations of $\mathrm{H}_{2} \mathrm{O}_{2}$ ( $\mathrm{n}=7-15$ for each group) was quantified. Nuclear condensation was measured $4 \mathrm{~h}$ after washout of $\mathrm{H}_{2} \mathrm{O}_{2}(10,30,50$ or 100 $\mu \mathrm{M}$ treatment for $1 \mathrm{~h}$ ) (B). The percentage of viable cells (M1), apoptotic fractions (M2) and necrotic fractions (M3) were examined by flow cytomery using an Annexin V assay (C-E). The viable, apoptotic and necrotic fractions in cardiomyocytes in the NOX4 $(\mathrm{n}=12)$, IH4 $(\mathrm{n}=$ 15) and NOX4+100 $\mu \mathrm{M} \mathrm{H}_{2} \mathrm{O}_{2}(\mathrm{n}=12)$ groups were quantified (F). ${ }^{*} p<0.05$ compared to control. Values are presented as means \pm SEM.

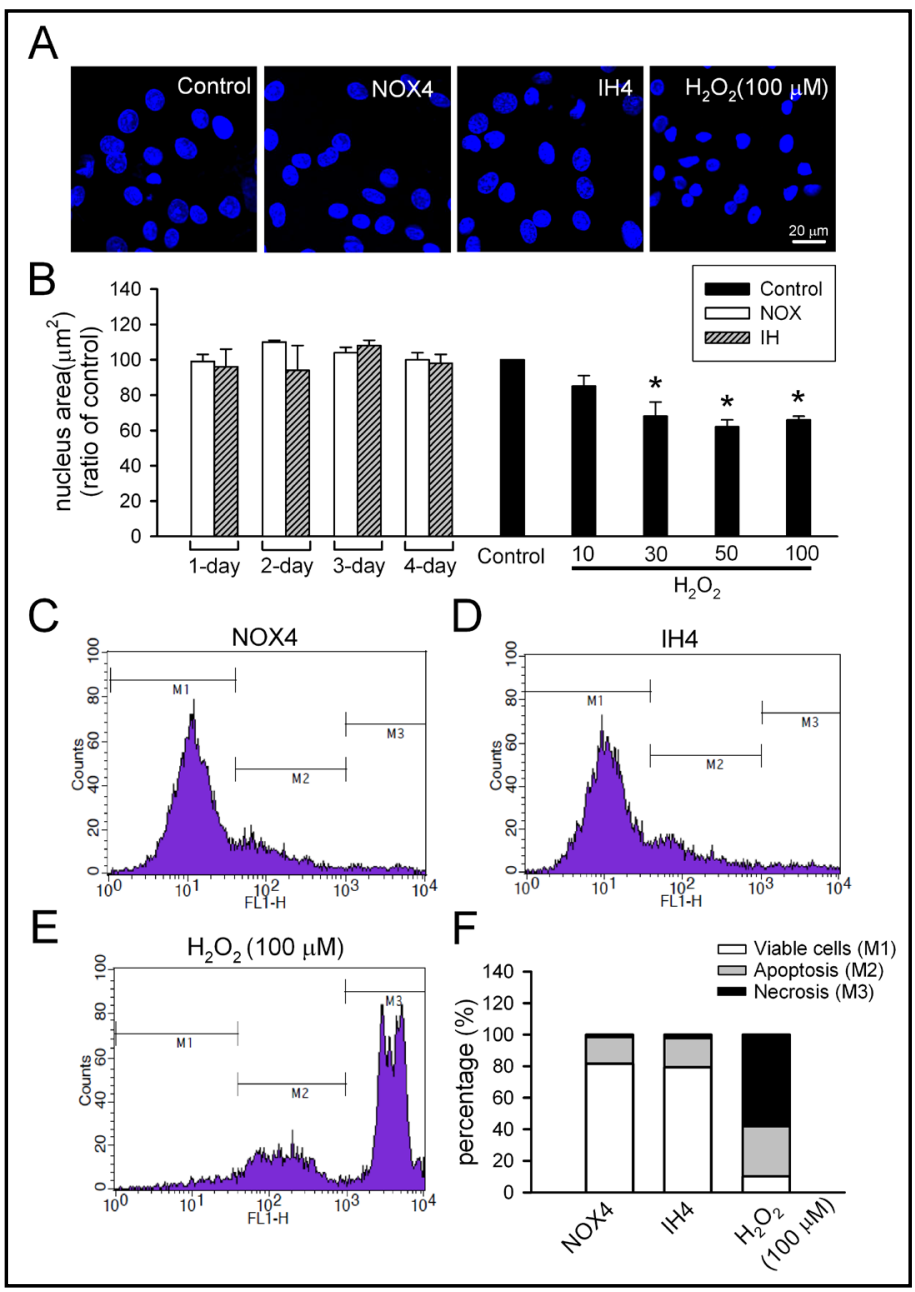

(Fig. 2C, 2D and 2F, both $p>0.05$ ). However, $100 \mu \mathrm{M} \mathrm{H}_{2} \mathrm{O}_{2}$ plus IH4 caused tremendous cell death in cardiomyocytes compared with NOX4 and IH4 (Fig. 2E and 2F, both $p<0.05$ ). These findings were consistent with the results shown in Fig. 2A and 2B. Therefore, our findings suggested that 4 days of IH exposure induced non-lethal ROS levels in rat neonatal cardiomyocytes.

IH increased total PKC $(\alpha, \beta, \gamma)$ protein expression and markedly induced translocation of the PKC isoforms from the cytosol to the plasma membrane in cardiomyocytes

The expression levels of PKC $(\alpha, \beta, \gamma)$ in cardiomyocytes significantly increased in the IH2, IH3 and IH4 groups compared with the NOX4 group (all $p<0.05$ ). However, significantly lower levels of the PKC isoforms were found in the IH4+Phen group than in the IH4 group. These findings indicated that Phen abolished the upregulation of PKC $(\alpha, \beta, \gamma)$ induced by IH $(p<0.05)$ (Fig. 3A and 3B). In addition, immunofluorescence images of PKC $(\alpha, \beta, \gamma)$ revealed that the PKC isoforms appeared to translocate to the plasma membrane in the IH4 group (Fig. 3C). Thus, cardiomyocytes were stained with $\beta$-catenin, a membrane marker, to determine whether the isoforms translocated from the cytosol to the plasma membrane. The merge image in Fig. 3D illustrates that staining for PKC $(\alpha, \beta, \gamma)$ overlaid that for $\beta$-catenin. In addition, the increased translocation of the PKC isoforms to the plasma membrane in the IH4 group was abolished by Phen and MnTBAP (Fig. 3C). Therefore, our results indicated that IH-induced increases in mitochondrial ROS generation increased the total levels of PKC $(\alpha, \beta$, $\gamma$ ) and activated these PKC isoforms in rat neonatal cardiomyocytes. 
Fig. 3. Intermittent hypoxia (IH)-induced increases in PKC $(\alpha, \beta, \gamma)$ expression and activation in cardiomyocytes. PKC $(\alpha, \beta, \gamma)$ protein expression in cardiomyocytes was examined by western blotting (A). The expression of total PKC $(\alpha, \beta, \gamma)$ protein in cardiomyocytes exposed to room air for 4 days (NOX4, $\mathrm{n}=7$ ), IH for $1-4$ days (IH1-4, n = 7 for each group) and IH4 plus 1,10-phenanthroline (IH4+Phen, $\mathrm{n}=6$ ) was quantified (B). Representative images of PKC $(\alpha, \beta, \gamma)$ expression (green) as examined using immunofluorescence staining and imaged by confocal microscopy (C). Representative image of PKC $(\alpha, \beta, \gamma)$ translocation from the cytosol to the plasma membrane, as confirmed by staining for PKC isozymes (green) and $\beta$-catenin (red) [the plasma membrane(PM) is denoted by white arrows] (D). ${ }^{*} p<0.05$ compared to NOX4; ${ }^{*} p<$ 0.05 compared to IH4. Values are presented as means \pm SEM.

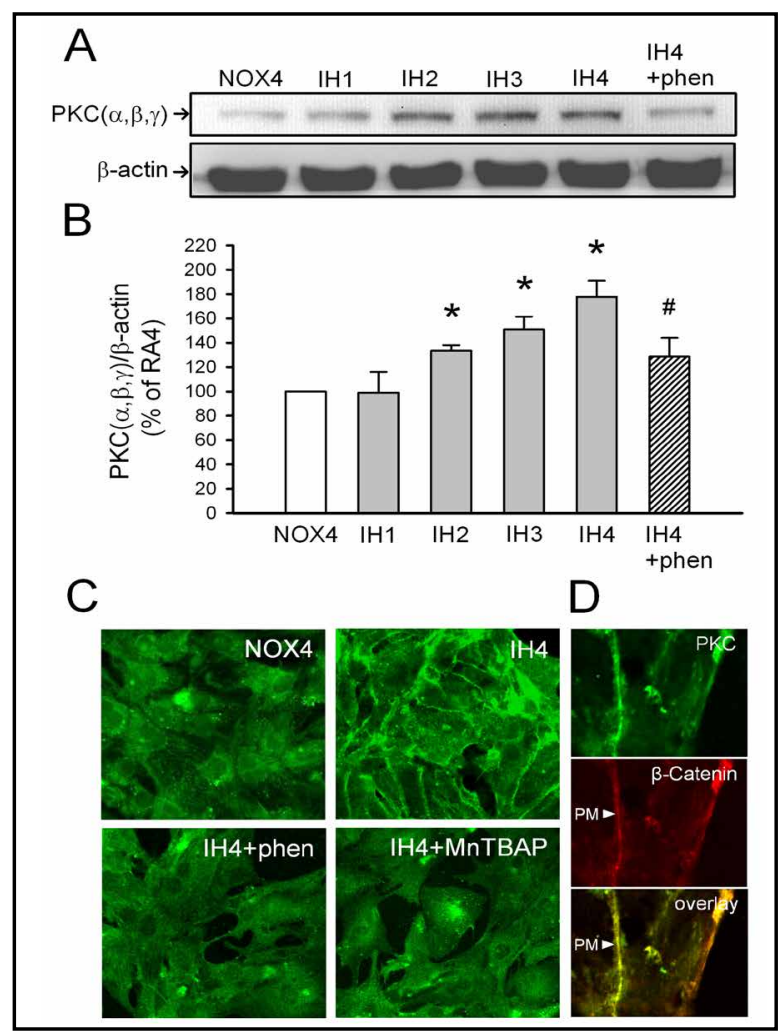

IH affected the $\mathrm{Ca}^{2+}$ efflux capacity for alleviating $\mathrm{KCl}$-induced $\mathrm{Ca}^{2+}$ accumulation in cardiomyocytes

A $40 \mathrm{mM} \mathrm{KCl}$ solution was used to assay alterations in $\left[\mathrm{Ca}^{2+}\right]_{\mathrm{i}}$ using the fluorescent $\mathrm{Ca}^{2+}$ indicator dye Fluo-3 AM and fluorescent microscope. The peak amplitude of $\left[\mathrm{Ca}^{2+}\right]_{\mathrm{i}}$ after $\mathrm{KCl}$ treatment did not differ between the IH and NOX groups on days 1-4, and no significant differences were found among any exposure days in the IH or NOX group (Fig. 4A and 4B). In addition, to determine whether ROS and PKC $(\alpha, \beta, \gamma)$ play a role in the effect of IH on KClmediated increases in $\left[\mathrm{Ca}^{2+}\right]_{i}, 100 \mathrm{nM}$ Phen and $5 \mu \mathrm{M}$ chelerythrine, a PKC inhibitor, were added daily in the $\mathrm{IH} 4$ groups (IH+Phen and $\mathrm{IH}+\mathrm{Che}$ groups, respectively). However, the $\mathrm{KCl}-$ induced peaks in $\left[\mathrm{Ca}^{2+}\right]_{\mathrm{i}}$ did not differ between the IH4 and IH4+Phen groups or between the IH4 and IH4+Che groups.

To maintain $\mathrm{Ca}^{2+}$ homeostasis in response to $\mathrm{KCl}$-induced increases in $\left[\mathrm{Ca}^{2+}\right]_{\mathrm{i}}$, cardiomyocytes activate two major mechanisms to decrease $\left[\mathrm{Ca}^{2+}\right]_{\mathrm{i}}$ : high $\left[\mathrm{Ca}^{2+}\right]_{\mathrm{i}}$-activated $\mathrm{Ca}^{2+}$ uptake by SR and $\mathrm{Ca}^{2+}$ efflux from the intracellular space to the extracellular space. The decay slopes of the $\mathrm{Ca}^{2+}$ indicator dye Fluo-3 AM were calculated at 0-30 s and 30-180 s after the initial increase in $\left[\mathrm{Ca}^{2+}\right]_{\mathrm{i}}$ induced by $\mathrm{KCl}$ to assess $\mathrm{Ca}^{2+}$ efflux capacity. Our results demonstrated that the rate constants of the $\left[\mathrm{Ca}^{2+}\right]_{\mathrm{i}}$ decay slopes at $0-30 \mathrm{~s}$ and $30-180 \mathrm{~s}$ after the initial induction by $\mathrm{KCl}$ were significantly higher in the IH group than in the NOX group on days 3-4 (both $p<0.05$ ) and lower in the IH+Phen and IH+Che groups than in the IH4 group (both $p<0.05$ ) (Fig. 4C and 4D). These results indicated that Phen and Che could abolish $\mathrm{Ca}^{2+}$ efflux induced by 4 days of $\mathrm{IH}$ exposure. In addition, the membrane potentialsensitive dye $\mathrm{DiBAC}_{4(3)}$ was used to confirm that $\mathrm{KCl}$ induced the same extent of plasma membrane depolarization in NOX4 and IH4 cardiomyocytes. We observed no differences in the plasma membrane potential between NOX4 and IH4 cardiomyocytes at depolarization (Fig. 4E and 4F), indicating that the enhancement of $\mathrm{Ca}^{2+}$ efflux induced by 3-4 days of $\mathrm{IH}$ exposure resulted from IH-induced ROS generation and PKC $(\alpha, \beta, \gamma)$ activation but not KClinduced depolarization-dependent increases in $\left[\mathrm{Ca}^{2+}\right]_{\mathrm{i}^{*}}$. Therefore, our findings suggested that $\mathrm{IH}$ affected the enhancement of $\mathrm{Ca}^{2+}$ efflux in response to $\mathrm{KCl}$-induced increases in $\mathrm{Ca}^{2+}$ levels in cardiomyocytes. 
Fig. 4. Intermittent hypoxia $(\mathrm{IH})$ enhanced the capacity of $\mathrm{Ca}^{2+}$ efflux mechanisms for alleviating $\mathrm{KCl}$-induced increases in intracellular $\mathrm{Ca}^{2+}$ concentrations $\left(\left[\mathrm{Ca}^{2+}\right]_{\mathrm{i}}\right)$ in cardiomyocytes. Representative $\mathrm{Ca}^{2+}$ transients, examined by live cell imaging in fluorescence microscopy using the Fluo-3 AM dye, induced by exposure to $40 \mathrm{mM}$ $\mathrm{KCl}$ in cardiomyocytes exposed to 4 days of normoxia (NOX4) or IH (IH4), IH4 plus 1,10-phenanthroline (IH4+Phen) or IH plus chelerythrine (IH4+Che) (A). Quantification of the peak $\left[\mathrm{Ca}^{2+}\right]_{\mathrm{i}}$ induced by $40 \mathrm{mM} \mathrm{KCl} \mathrm{(B)} \mathrm{and} \mathrm{the} \mathrm{velocity}$ of $\mathrm{Ca}^{2+}$ efflux as represented by the decay slopes at 0-30 s (C) and 30-180 s (D) following $40 \mathrm{mM}$ KCl-induced increases in $\left[\mathrm{Ca}^{2+}\right]_{i}$ in HEPES-buffered Tyrode's solution in cardiomyocytes exposed to normoxia for 1-4 days, IH for 1-4 days and IH4+Phen and IH4+Che ( $n=7-15$ for each group). Representative changes in membrane potentials, examined by live cell

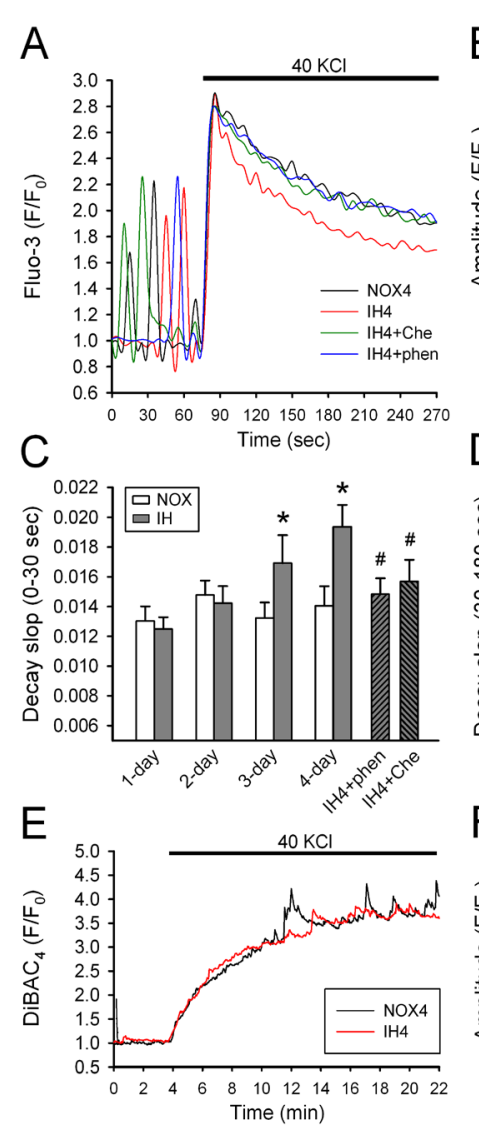

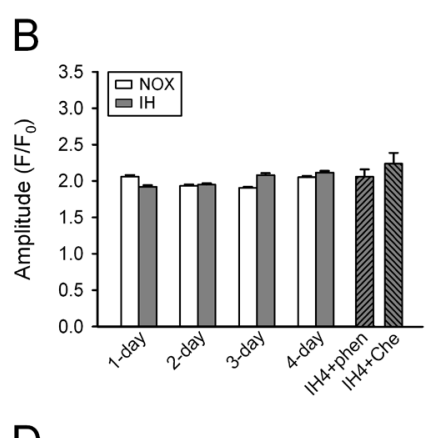

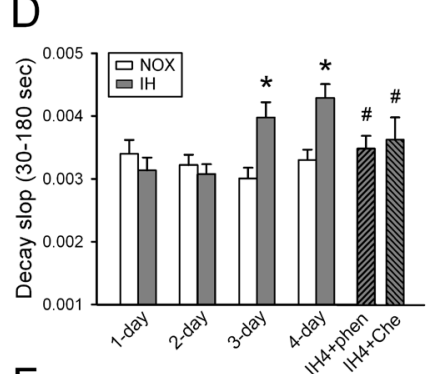

F

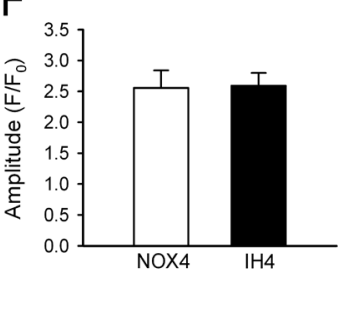

imaging in fluorescence microscopy using the $\mathrm{DiBAC}_{4(3)}$ dye, induced by $40 \mathrm{mM} \mathrm{KCl} \mathrm{(E).} \mathrm{Quantification} \mathrm{of}$ membrane depolarization induced by $40 \mathrm{mM} \mathrm{KCl}$ in cardiomyocytes in the NOX4 $(\mathrm{n}=11)$ and IH4 groups ( $\mathrm{n}=12$ ) (F). ${ }^{*} p<0.05$ compared to the NOX group on the same exposure day; ${ }^{*} p<0.05$ compared to IH exposure for 4 days. Values are presented as means \pm SEM.

\section{IH induced NCX-1 activation in cardiomyocytes}

To examine whether NCX played a role in IH-enhanced $\mathrm{Ca}^{2+}$ efflux, HEPES-buffered Tyrode's solution perfusion buffer was replaced by a $\mathrm{Na}^{+}$-free buffer or KBR7943 (an NCX transport inhibitor) to inhibit the function of NCX when cardiomyocytes were perfused with $40 \mathrm{mM} \mathrm{KCl}$. Our results revealed no differences in the $\mathrm{KCl}$-induced $\mathrm{Ca}^{2+}$ peaks between the IH4 and NOX4 groups in HEPES buffer as well as in $\mathrm{Na}^{+}$-free or KBR7943 buffer (Fig. 5A). Both decay slopes at 0-30 s and 30-180 s after the initial induction by $\mathrm{KCl}$ in the IH4 group were significantly higher than those in the NOX4 group perfused with HEPES buffer. However, the decay slopes did not differ between the IH4 and NOX4 groups perfused with $\mathrm{Na}^{+}$-free and KBR7943 buffers (Fig. 5B and 5C). These results indicated that NCX might play a role in the enhancement of $\mathrm{Ca}^{2+}$ efflux in cardiomyocytes induced by 4 days of IH exposure. Next, the mRNA and protein levels of NCX-1 were examined to confirm the role of NCX-1 in $\mathrm{Ca}^{2+}$ efflux in IH-exposed cardiomyocytes. Our results clarified that the mRNA and protein levels of NCX-1 were significantly increased in the IH4 group compared with the NOX4 group ( $p<$ $0.05)$. Concerning the protein levels, significantly lower NCX-1 levels were measured in the $\mathrm{IH}+$ Phen group $(p<0.05)$ (Fig. 5D and 5E). We further examined NCX-1 levels expressed on cardiomyocyte membranes using immunocytofluorescence. Our results indicated that NCX1 levels on cardiomyocyte membranes (white arrows) were significantly higher in the IH4 group than in the NOX4 group (Fig. 5F). Thus, IH activated NCX-1, contributing to increases in the $\mathrm{Ca}^{2+}$-handling ability to relieve the KCl-induced increases in $\left[\mathrm{Ca}^{2+}\right]_{\mathrm{i}}$ associated with $\mathrm{IH}$ mediated increases in ROS generation in cardiomyocytes. 


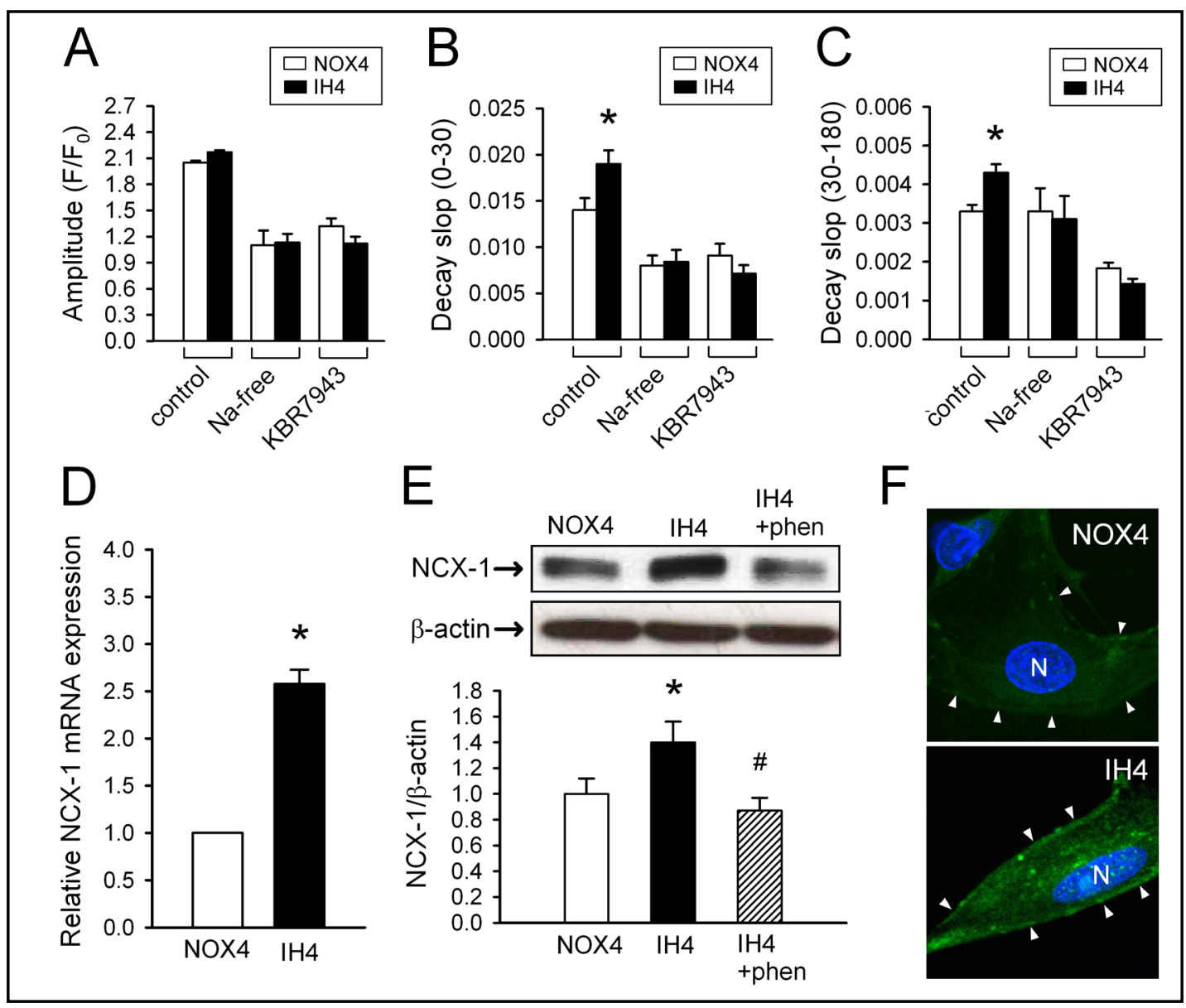

Fig. 5. Intermittent hypoxia (IH)-induced increases in NCX-1 activation contribute to increases in $\mathrm{Ca}^{2+} \mathrm{efflux}^{\mathrm{N}}$ capacity in cardiomyocytes. Quantification of peak intracellular calcium concentrations $\left[\mathrm{Ca}^{2+}\right]_{\mathrm{i}^{\prime}}$, examined by live cell imaging in fluorescence microscopy using the Fluo-3 AM dye, induced by exposure to $40 \mathrm{mM}$ $\mathrm{KCl}(\mathrm{A})$ and the velocity of $\mathrm{Ca}^{2+}$ efflux as represented by the decay slopes at 0-30 s (B) and 30-180 s (C) following $40 \mathrm{mM} \mathrm{KCl}$-induced increases in $\left[\mathrm{Ca}^{2+}\right]_{\mathrm{i}}$ in HEPES-buffered Tyrode's (control), $\mathrm{Na}^{+}$-free buffer and KBR7943 buffer in cardiomyocytes exposed to 4 days of normoxia (NOX4) or IH (IH4) (n = 7-15 for each group). Quantification of NCX-1 mRNA expression in cardiomyocytes in the NOX4 $(n=12)$ and IH4 groups $(n=12)(D)$. Representative western blotting images and quantification of NCX-1 protein expression in cardiomyocytes in the NOX4 ( $n=5)$, IH4 $(n=5)$ and IH4 plus 1,10-phenanthroline (IH4+Phen) groups $(n=$ 5) (E). Representative images of NCX-1 expression (green) on the plasma membrane (white arrowheads) as determined by immunofluorescence and imaged by confocal microscopy (F). N: nucleus (blue). ${ }^{*} p<0.05$ compared to NOX4; ${ }^{*} p<0.05$ compared to IH4. Values are presented as means \pm SEM.

\section{IH induced enhancement of $\mathrm{Ca}^{2+}$-mediated SR regulation in cardiomyocytes}

In this study, $\mathrm{Ca}^{2+}$-mediated SR regulation was examined using thapsigargin (TG) to block $\mathrm{Ca}^{2+}$ uptake by SR before cardiomyocytes were perfused with $\mathrm{Na}^{+}$-free buffer. The peak amplitude of $\left[\mathrm{Ca}^{2+}\right]_{\mathrm{i}}$ after $\mathrm{Na}^{+}$-free treatment did not differ between the NOX4 and IH4 groups, and no significant differences were found in TG-treated or untreated cardiomyocytes in the IH4 or NOX4 group. The rate constants of the $\left[\mathrm{Ca}^{2+}\right]_{\mathrm{i}}$ decay slopes at $0-120 \mathrm{~s}$ after the initial induction by $\mathrm{Na}^{+}$-free treatment were significantly higher in the IH4 group than in the NOX4 group $(p<0.05)$. This effect was abolished by TG treatment (Fig. 6A-C). Next, 20 $\mathrm{mM}$ caffeine, a RyR agonist [26], was used to induce the opening of RyRs on SR following cardiomyocyte perfusion with $\mathrm{Ca}^{2+}$-free HEPES-buffered Tyrode's solution to remove 
Fig. 6. Intermittent hypoxia $(\mathrm{IH})$ enhanced the $\mathrm{Ca}^{2+}$ release capacity of SR in cardiomyocytes. Representative $\mathrm{Ca}^{2+}$ transients, examined by live cell imaging in fluorescence microscopy using the Fluo-3 AM dye, in cardiomyocytes treated with thapsigargin (TG) to block $\mathrm{Ca}^{2+}$ uptake by SR before perfusion with $\mathrm{Na}^{+}$-free buffer (A). Quantification of peak intracellular calcium transients induced by $\mathrm{Na}^{+}$-free buffer (B) and the velocity of $\mathrm{Ca}^{2+}$ uptake by SR as represented by the decay slopes at 0-120 s (C) following $\mathrm{Na}^{+}$-free bufferinduced increases in $\left[\mathrm{Ca}^{2+}\right]_{\mathrm{i}}$ in cardiomyocytes exposed to 4 days of normoxia (NOX4), NOX4 plus TG (NOX4+TG), 4 days of IH (IH4) and IH4 plus TG (IH4+TG) ( $\mathrm{n}=8-10$ for each group). Representative $\mathrm{Ca}^{2+}$ transients induced by $20 \mathrm{mM}$ caffeine in cardiomyocytes perfused with $\mathrm{Ca}^{2+}$-free 0.2 $\mathrm{mM}$ ethyleneglycol-bis

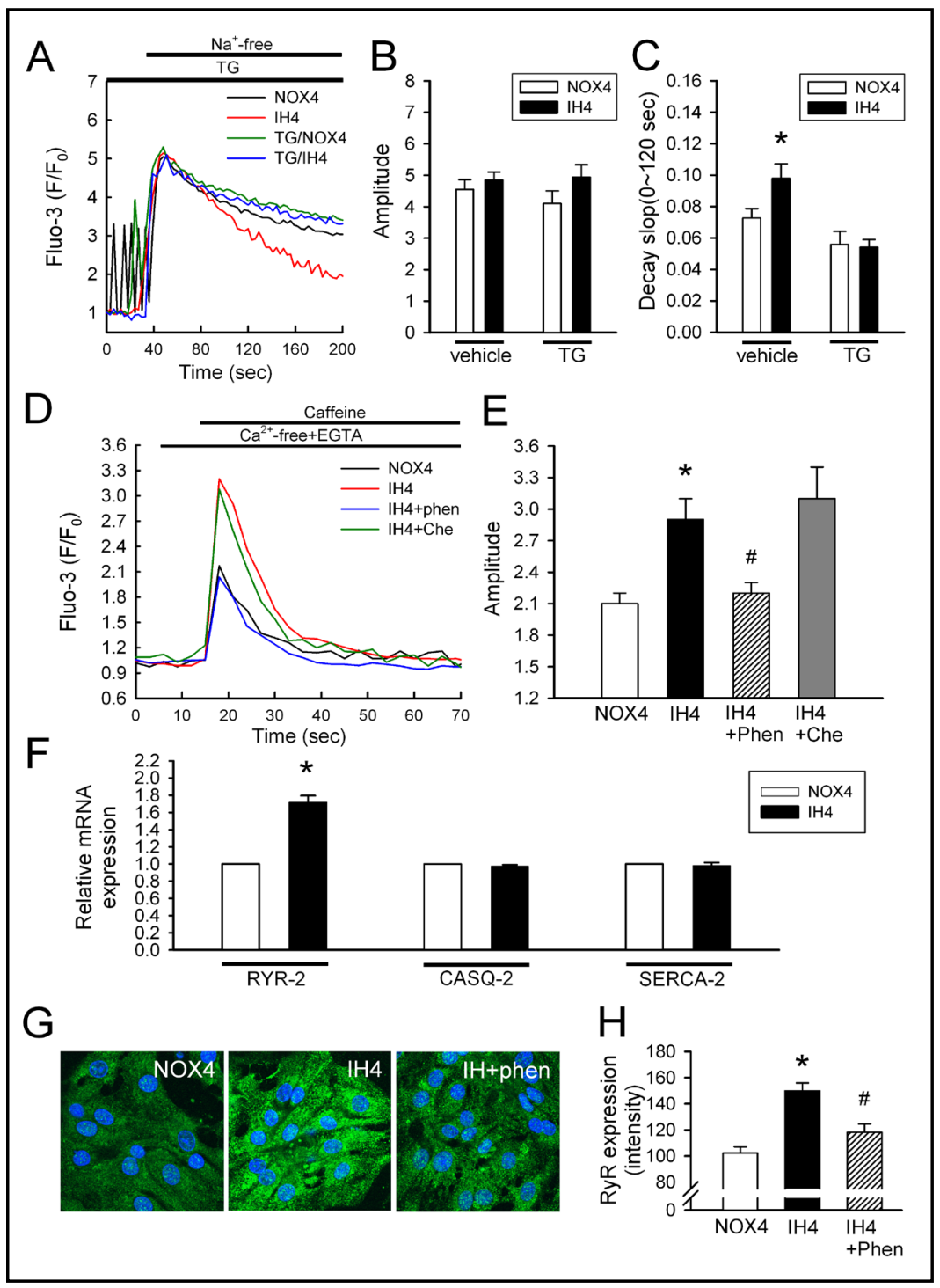

(beta-aminoethylether)-N, N'-tetraacetic acid ( $\mathrm{Ca}^{2+}$-free+EGTA) solution in the NOX4, IH4, IH4 plus $100 \mathrm{nM}$ 1,10-phenanthroline (IH4+Phen) and IH4 plus $5 \mathrm{mM}$ chelerythrine (IH4+Che) groups (D). Quantification of the $\mathrm{Ca}^{2+}$ storage capacity of SR as represented by the amplitude of the $\mathrm{Ca}^{2+}$ peak induced by $20 \mathrm{mM}$ caffeine in the NOX4 ( $=31)$, IH4 $(n=42)$, IH4+Phen $(n=25)$ and IH4+Che groups $(n=8)(E)$. Quantification of ryanodine receptor 2 (RyR-2) (NOX4, $\mathrm{n}=15$; IH4, $\mathrm{n}=15$ ), calsequestrin-2 (CASQ-2) (NOX4, $\mathrm{n}=13 ; \mathrm{IH} 4, \mathrm{n}=$ 13) and sarco/endoplasmic reticulum $\mathrm{Ca}^{2+}$-ATPase 2 (SERCA-2) (NOX4, $\mathrm{n}=12 ; \mathrm{IH} 4, \mathrm{n}=12$ ) mRNA expression in cardiomyocytes exposed in the NOX4 and IH4 groups (F). Representative images of RyR-2 fluorescence staining imaged by confocal microscopy $(G)$ and quantification of RyR-2 protein expression levels as represented by immunofluorescence intensity in cardiomyocytes in the NOX4 ( $=21)$, IH4 $(n=18)$ and IH4+Phen groups $(\mathrm{n}=18)(\mathrm{H})$. N: nucleus (blue). ${ }^{*} p<0.05$ compared to NOX4; $p<0.05$ compared to IH4. Values are presented as means \pm SEM.

cytosolic $\mathrm{Ca}^{2+}$. Our results demonstrated that the caffeine-induced increase in the $\mathrm{Ca}^{2+}$ transient amplitude, representing the $\mathrm{Ca}^{2+}$-handling ability of SR, was significantly higher in the IH4 group than that in the NOX4 group $(p<0.05)$. A significantly lower $\mathrm{Ca}^{2+}$ transient amplitude was noted in the IH+Phen group than in the IH4 group ( $p<0.05)$, whereas no difference was observed between the IH4+Che and IH4 groups ( $p>0.05)$ (Fig. 6D and 6E). Next, we examined the mRNA expression of RyR-2, calsequestrin-2 (CASQ-2) and SERCA-2 
in SR in IH-induced cardiomyocytes. Figure 6F reveals that the mRNA expression levels of RyR-2 were significantly higher in the IH4 group than in the NOX4 group $(p<0.05)$; however, no difference was found in the mRNA expression levels of CASQ-2 and SERCA-2 between the two groups $(p>0.05)$. In addition, we used an immunocytofluorescence stain to further confirm the protein expression levels of RyR-2 in cardiomyocytes. Our results indicated that the protein expression levels of RyR-2 in SR were significantly increased in the IH4 group compared with the NOX4 group $(p<0.05)$ (Fig. 6G). However, significantly lower protein expression levels of RyR-2 were observed in the IH4+Phen group $(p<0.05)$ (Fig. $6 \mathrm{H})$. Therefore, our results indicated that IH-induced increases in ROS generation played a role in the IH-induced augmentation of RyR-2 mRNA and protein expression and the activity of RyR-2 and SERCA-2, contributing to the increase in $\mathrm{Ca}^{2+}$-mediated SR regulation in $\mathrm{IH}$ exposed cardiomyocytes.

\section{Discussion}

A cell culture model of IH might provide further insight into the cellular mechanisms associated with $\mathrm{Ca}^{2+}$ regulation during adaptation to $\mathrm{IH}$ in cardiomyocytes. The phenotype of cultured neonatal cardiomyocytes is extremely stable, and their contractile profile during hypoxia-re-oxygenation is comparable to that of in situ hearts during I/R [27]. Previous findings indicated that hypoxic stress is not associated with any significant metabolic, structural or functional damage in cardiomyocytes [28]. In this study, spontaneous contractile activity remained stable up to 4 days in cultured neonatal cardiomyocytes exposed to NOX or IH. In addition, our major findings provide evidence that IH-induced non-lethal oxidative stress generation increased PKC $(\alpha, \beta, \gamma)$ expression, which resulted in increased NCX-1 expression and activity, leading to enhanced $\mathrm{Ca}^{2+}$ efflux capacity. Simultaneously, the IHinduced increases in SERCA and RyR-2 activities and RyR-2 expression resulted in improved $\mathrm{Ca}^{2+}$ storage and release capacity of SR in cardiomyocytes. These alterations worked to strengthen the $\mathrm{Ca}^{2+}$-handling ability of cardiomyocytes.

There are at least two types of IH: acute intermittent hypoxia (AIH; several episodes over a short period) and chronic intermittent hypoxia (CIH; lasting several days or weeks). Both AIH and CIH essentially involve recurrent re-oxygenation episodes, leading to increased intracellular oxidative stress generation [29]. The burst of ROS generation observed during hypoxia-re-oxygenation is considered one of the key factors in cell injury. Mild ROS generation can also be protective in a pre-conditioning-like manner and induce stress responses, leading to survival [9]. However, increases in infarct size induced by I/R were found in the hearts of rats exposed to IH induced by exposure to $5 \% \mathrm{O}_{2}$ for $4 \mathrm{~h}$ [30] and 35 consecutive days ( $8 \mathrm{~h} /$ day) [1]. Of note, IH pre-conditioning with $10 \% \mathrm{O}_{2}$ for $4 \mathrm{~h}$ induces cardioprotection, as illustrated by a reduction in infarct size in isolated rat hearts [30]. These cardioprotective effects were also observed after chronic IH induced by exposure to $9.5-10 \%$ $\mathrm{O}_{2}$ for 20 consecutive days (25-70 min/day) [31]. These effects were observed probably because of the correlation between significant increases in cellular ROS generation and the degree of hypoxia compared with the degree of normoxia [20]. In this study, IH induced by 1-4 days of exposure to $9 \% \mathrm{O}_{2}$ dissolved in the culture medium did not increase cell death in cardiomyocytes, possibly because $9 \% \mathrm{O}_{2}$ dissolved in medium did not cause a burst of ROS generation in cardiomyocytes. Thus, cardiomyocytes were treated with $\mathrm{H}_{2} \mathrm{O}_{2}(10,30$, 50 and $100 \mu \mathrm{M}$ ) to mimic different degrees of ROS-induced cardiomyocyte death. $\mathrm{H}_{2} \mathrm{O}_{2}$ induced ROS generation, which significantly increases cell death in cardiomyocytes, was not noted at lower concentrations (approximately $10 \mu \mathrm{M}$ ) [20,32] but was observed at higher concentrations $(>50 \mu \mathrm{M})[33,34]$. Compared with the number of cardiomyocytes treated with $10 \mu \mathrm{M} \mathrm{H}_{2} \mathrm{O}_{2}$, the number of cardiomyocytes was not decreased by 4 days of IH exposure, which suggests that 4 days of $\mathrm{IH}$ induces non-lethal oxidative stress in cardiomyocytes.

Oxidative stress during adaptation to IH plays an important role in the induction of endogenous PKC isozymes [8]. Furthermore, diacylglycerol and phospho- 
lipase C phosphorylation induced by ROS increase PKC activation [8, 35, 36]. In both neonatal and adult ventricular myocytes, the conventional PKC isozymes $(\alpha$, $\beta, \gamma)$ can be activated by ROS [8,35,36], $\mathrm{Ca}^{2+}$ and lipid [37] through translocation of the isozymes from the cytosol to the plasma membrane [38]. PKC also plays important regulatory roles in the upregulation of cardiac NCX-1 [39], the stimulation of $\mathrm{Ca}^{2+}$-pumping ATPases [40] and the function of cardiac SR $\mathrm{Ca}^{2+}$ release channels in heart tissue, resulting in an increase in the $\mathrm{Ca}^{2+}$-handling ability $[41,42]$, which may help to prevent $\mathrm{Ca}^{2+}$ overload-induced cell death [32].

Of note, under physiological conditions, increases in myocardial force production and power output in cardiomyoyctes are associated with a faster rise and decay of the intracellular calcium transients and improved myofilament sensitivity to calcium [17]. However, these capacity were not observed in adult cardiomyocytes isolated from rats exposed to IH for 7 days [18] or rats exposed to intermittent high-altitude hypoxia for 42 days [11]. In this study, to examine $\mathrm{Ca}^{2+}$-handling ability in IH-exposed cardiomyocytes, we used high $\mathrm{K}^{+}$[43] to increase $\left[\mathrm{Ca}^{2+}\right]_{i}$ to activate the $\mathrm{Ca}^{2+}$ efflux mechanism [44] and $\mathrm{Ca}^{2+}$ uptake by SR [45]. Our findings showed that IH did not alter voltage-gated $\mathrm{Ca}^{2+}$ channel opening, resulting in a similar degree of $\mathrm{Ca}^{2+}$ influx into cardiomyocytes as that induced by $\mathrm{KCl}$. Conversely, to reduce cytosolic $\mathrm{Ca}^{2+}$ levels in cardiomyocytes, $\mathrm{Ca}^{2+}$ is removed via $\mathrm{NCX}$ and taken up into SR [45]. Thus, IH-induced ROS generation plays a role in increasing NCX activation by PKC $(\alpha, \beta, \gamma)$ and enhancing SERCA activity, helping to enhance the removal of cytosolic $\mathrm{Ca}^{2+}$.

It is well known that CASQ2 is a high-capacity $\mathrm{Ca}^{2+}$-binding protein expressed inside SR [46]. CASQ-2 binds RyR-2 to form the SR luminal RyR-2 $\mathrm{Ca}^{2+}$ release channel complex, which participates in regulating $\mathrm{Ca}^{2+}$ release from SR [47]. Further, SR is the primary component responsible for $\mathrm{Ca}^{2+}$ storage that plays a key role in the maintenance of intracellular $\mathrm{Ca}^{2+}$ homeostasis in cardiomyocytes [48]. In this study, the amplitude of caffeine-stimulated $\mathrm{Ca}^{2+}$ transients in IH-exposed cardiomyocytes for 4 days was significantly increased compared with that in cardiomyocetes under normoxia. RyR-2 expression was increased by IH. However, CSAQ-2 and SERCA-2 mRNA expression was unaltered in IH-exposed cardiomyocytes. These findings suggest that the increased caffeine-stimulated $\mathrm{Ca}^{2+}$ transients in cardiomyocytes result from increases in $\mathrm{Ca}^{2+}$ release by SR. Thus, our findings indicate that ROS generation induced by 4 days of IH exposure enhances RyR-2 activity and expression levels, resulting in increased $\mathrm{Ca}^{2+}$ release by SR in cardiomyocytes.

In summary, IH induced a mild increase in ROS generation that did not cause cardiomyocyte death. The non-lethal ROS level helped, in part, to increase PKC $(\alpha, \beta, \gamma)$ protein expression and translocation, resulting in increased NCX-1expression and activity and leading to enhanced $\mathrm{Ca}^{2+}$ efflux from the cytosol to the extracellular milieu. In addition, $\mathrm{Ca}^{2+}$ uptake and release by SR were significantly enhanced by IH because of the increased SERCA and RyR-2 activities and RyR-2 expression levels induced by mildly increased ROS generation. In conclusion, this study suggests that $\mathrm{IH}$ can promote the $\mathrm{Ca}^{2+}$-handling ability of rat neonatal cardiomyocytes by mildly increasing ROS generation, resulting in enhanced $\mathrm{Ca}^{2+}$ efflux from the cytosol to the extracellular milieu and increased $\mathrm{Ca}^{2+}$ release and storage by SR.

\section{Limitations}

Although the use of animal models to study cardiac diseases has become standard in cardiovascular research [49], it is difficult to analyse $\mathrm{Ca}^{2+}$ regulation in the whole hearts or animals. Recently, multiparametric electrophysiological imaging of the mammalian heart was developed to detect $\mathrm{Ca}^{2+}$ transients in vivo; however, this measurement is difficult to apply under IH. Conversely, freshly isolated adult or cultured neonatal rat cardiomyocytes have proven useful for analysing states of oxygen and volume restriction conditions that are known to stimulate anoxia and ischaemia at the cellular level, respectively [50]. However, in freshly isolated cardiomyocytes, membrane proteins, such as receptors and ion channels, are damaged during the enzymatic isolation procedure [51]. These impairments of membrane proteins might prevent the adaptation of cardiomyocytes to IH under physiological 
conditions. For instance, IH-induced enhanced $\mathrm{Ca}^{2+}$ handling was observed under I/R but not at pre-I/R in adult cardiomyocytes isolated from rats exposed to IH for 7 [18] or 42 days [11]. In this study, although neonatal cardiomyocytes exposed to IH provided a convenient method for investigating the mechanisms of IH-induced cardiomyocyte injuries, other physiological events, such as cardiovascular circulation and hormone production, must be considered when our findings are applied to systematic physiology.

\section{Acknowledgements}

This study was supported by National Science Council, Taiwan, Grant NSC 95-2314B-320-019, NSC 96-2320-B-320-017-MY2 and NSC 100-2410-H-320-013, and by Tzu Chi University, Taiwan, Grant TCRPP-100007, TCIRP-95004-05 and TCMRC-P-99008.

\section{References}

1 Joyeux-Faure M, Stanke-Labesque F, Lefebvre B, Beguin P, Godin-Ribuot D, Ribuot C, Launois SH, Bessard G, Levy P: Chronic intermittent hypoxia increases infarction in the isolated rat heart. J Appl Physiol 2005;98:1691-1696.

2 Manukhina EB, Downey HF, Mallet RT: Role of nitric oxide in cardiovascular adaptation to intermittent hypoxia. Exp Biol Med (Maywood) 2006;231:343-365.

-3 Chiu SC, Huang SY, Tsai YC, Chen SP, Pang CY, Lien CF, Lin YJ, Yang KT: Poly (adp-ribose) polymerase plays an important role in intermittent hypoxia-induced cell death in rat cerebellar granule cells. J Biomed Sci 2012;19:29.

4 Rey S, Del Rio R, Alcayaga J, Iturriaga R: Chronic intermittent hypoxia enhances cat chemosensory and ventilatory responses to hypoxia. J Physiol 2004;560:577-586.

$>5$ Chen TI, Lai CJ, Hsieh CJ, Tsai KL, Yang KT: Differences in left ventricular cardiomyocyte loss induced by chronic intermittent hypoxia between spontaneously hypertensive and wistar-kyoto rats. Sleep Breath 2011;15:845-854.

6 Williams AL, Chen L, Scharf SM: Effects of allopurinol on cardiac function and oxidant stress in chronic intermittent hypoxia. Sleep Breath 2010;14:51-57.

7 Kolar F, Ostadal B: Molecular mechanisms of cardiac protection by adaptation to chronic hypoxia. Physiol Res 2004;53:S3-13.

8 Kolar F, Jezkova J, Balkova P, Breh J, Neckar J, Novak F, Novakova O, Tomasova H, Srbova M, Ost'adal B, Wilhelm J, Herget J: Role of oxidative stress in pkc-delta upregulation and cardioprotection induced by chronic intermittent hypoxia. Am J Physiol Heart Circ Physiol 2007;292:H224-230.

-9 Becker LB: New concepts in reactive oxygen species and cardiovascular reperfusion physiology. Cardiovasc Res 2004;61:461-470.

10 Dematteis M, Godin-Ribuot D, Arnaud C, Ribuot C, Stanke-Labesque F, Pepin JL, Levy P: Cardiovascular consequences of sleep-disordered breathing: Contribution of animal models to understanding the human disease. ILAR 2009;50:262-281.

11 Chen L, Lu XY, Li J, Fu JD, Zhou ZN, Yang HT: Intermittent hypoxia protects cardiomyocytes against ischemia-reperfusion injury-induced alterations in $\mathrm{Ca}^{2+}$ homeostasis and contraction via the sarcoplasmic reticulum and $\mathrm{Na}^{+} / \mathrm{Ca}^{2+}$ exchange mechanisms. Am J Physiol Cell Physiol 2006;290:C1221-1229.

-12 Kiriazis H, Kranias EG: Genetically engineered models with alterations in cardiac membrane calciumhandling proteins. Annu Rev Physiol 2000;62:321-351.

13 Frank KF, Bolck B, Erdmann E, Schwinger RH: Sarcoplasmic reticulum $\mathrm{Ca}^{2+}$-atpase modulates cardiac contraction and relaxation. Cardiovasc Res 2003;57:20-27.

14 Woodcock EA, Matkovich SJ: Cardiomyocytes structure, function and associated pathologies. Int J Biochem Cell Biol 2005;37:1746-1751.

15 Osada M, Netticadan T, Tamura K, Dhalla NS: Modification of ischemia-reperfusion-induced changes in cardiac sarcoplasmic reticulum by preconditioning. Am J Physiol 1998;274:H2025-2034. 


\section{Cellular Physiology Cell Physiol Biochem 2014;33:513-527 and Biochemistry

16 Zhu WZ, Xie Y, Chen L, Yang HT, Zhou ZN: Intermittent high altitude hypoxia inhibits opening of mitochondrial permeability transition pores against reperfusion injury. J Mol Cell Cardiol 2006;40:96-106.

17 Kemi OJ, Ellingsen O, Smith GL, Wisloff U: Exercise-induced changes in calcium handling in left ventricular cardiomyocytes. Front Biosci 2008;13:356-368.

18 Yeung HM, Kravtsov GM, Ng KM, Wong TM, Fung ML: Chronic intermittent hypoxia alters ca2+ handling in rat cardiomyocytes by augmented $\mathrm{Na}^{+} / \mathrm{Ca}^{2+}$ exchange and ryanodine receptor activities in ischemiareperfusion. Am J Physiol Cell Physiol 2007;292:C2046-2056.

19 Beguin PC, Belaidi E, Godin-Ribuot D, Levy P, Ribuot C: Intermittent hypoxia-induced delayed cardioprotection is mediated by pkc and triggered by p38 map kinase and erk1/2. J Mol Cell Cardiol 2007;42:343-351.

20 Duranteau J, Chandel NS, Kulisz A, Shao Z, Schumacker PT: Intracellular signaling by reactive oxygen species during hypoxia in cardiomyocytes. J Biol Chem 1998;273:11619-11624.

$21 \mathrm{Mu}$ X, Harvey P: Estrogen differentially affects expression of calcium handling genes in female and male adult cardiomyocytes. J Stud Res 2012;1:31-37.

-22 Yang KT, Chang WL, Yang PC, Chien CL, Lai MS, Su MJ, Wu ML: Activation of the transient receptor potential $\mathrm{m} 2$ channel and poly(adp-ribose) polymerase is involved in oxidative stress-induced cardiomyocyte death. Cell Death Differ 2006;13:1815-1826.

23 Chilton L, Ohya S, Freed D, George E, Drobic V, Shibukawa Y, Maccannell KA, Imaizumi Y, Clark RB, Dixon IM, Giles WR: $\mathrm{K}^{+}$currents regulate the resting membrane potential, proliferation, and contractile responses in ventricular fibroblasts and myofibroblasts. Am J Physiol Heart Circ Physiol 2005;288:H2931-2939.

24 Kuroda H, Sobhan U, Sato M, Tsumura M, Ichinohe T, Tazaki M, Shibukawa Y: Sodium-calcium exchangers in rat trigeminal ganglion neurons. Mol Pain 2013;9:22.

-25 Zeiger U, Mitchell CH, Khurana TS: Superior calcium homeostasis of extraocular muscles. Exp Eye Res 2010;91:613-622.

-26 Anyatonwu GI, Estrada M, Tian X, Somlo S, Ehrlich BE: Regulation of ryanodine receptor-dependent calcium signaling by polycystin-2. Proc Natl Acad Sci USA 2007;104:6454-6459.

27 Yamashita N, Nishida M, Hoshida S, Kuzuya T, Hori M, Taniguchi N, Kamada T, Tada M: Induction of manganese superoxide dismutase in rat cardiac myocytes increases tolerance to hypoxia 24 hours after preconditioning. J Clin Invest 1994;94:2193-2199.

28 Goldberg M, Zhang HL, Steinberg SF: Hypoxia alters the subcellular distribution of protein kinase c isoforms in neonatal rat ventricular myocytes. J Clin Invest 1997;99:55-61.

29 McGuire M, Zhang Y, White DP, Ling L: Chronic intermittent hypoxia enhances ventilatory long-term facilitation in awake rats. J Appl Physiol 2003;95:1499-1508.

30 Beguin PC, Joyeux-Faure M, Godin-Ribuot D, Levy P, Ribuot C: Acute intermittent hypoxia improves rat myocardium tolerance to ischemia. J Appl Physiol 2005;99:1064-1069.

-31 Zong P, Setty S, Sun W, Martinez R, Tune JD, Ehrenburg IV, Tkatchouk EN, Mallet RT, Downey HF: Intermittent hypoxic training protects canine myocardium from infarction. Exp Biol Med (Maywood) 2004;229:806-812.

-32 Yang KT, Pan SF, Chien CL, Hsu SM, Tseng YZ, Wang SM, Wu ML: Mitochondrial $\mathrm{Na}^{+}$overload is caused by oxidative stress and leads to activation of the caspase 3- dependent apoptotic machinery. FASEB J 2004;18:1442-1444.

-33 Koyama Y, Takeishi Y, Takahashi H, Shishido T, Arimoto T, Niizeki T, Harada M, Suzuki S, Kitahara T, Sasaki T, Kubota I: Azelnidipine inhibits h2o2-induced cell death in neonatal rat cardiomyocytes. Cardiovasc Drugs Ther 2007;21:69-72.

-34 Yu W, Fu YC, Zhou XH, Chen CJ, Wang X, Lin RB, Wang W: Effects of resveratrol on $\mathrm{H}_{2} \mathrm{O}_{2}$-induced apoptosis and expression of sirts in h9c2 cells. J Cell Biochem 2009;107:741-747.

-35 Bouwman RA, Musters RJ, van Beek-Harmsen BJ, de Lange JJ, Boer C: Reactive oxygen species precede protein kinase c-delta activation independent of adenosine triphosphate-sensitive mitochondrial channel opening in sevoflurane-induced cardioprotection. Anesthesiology 2004;100:506-514.

-36 Otani H: Reactive oxygen species as mediators of signal transduction in ischemic preconditioning. Antioxid Redox Signal 2004;6:449-469. 
Chen et al.: Intermittent Hypoxia Alters $\mathrm{Ca}^{2+}$ Homeostasis in Cardiomyocytes

-37 Braz JC, Gregory K, Pathak A, Zhao W, Sahin B, Klevitsky R, Kimball TF, Lorenz JN, Nairn AC, Liggett SB, Bodi I, Wang S, Schwartz A, Lakatta EG, DePaoli-Roach AA, Robbins J, Hewett TE, Bibb JA, Westfall MV, Kranias EG, Molkentin JD: Pkc-alpha regulates cardiac contractility and propensity toward heart failure. Nat Med 2004;10:248-254.

-38 Ding HL, Zhu HF, Dong JW, Zhu WZ, Zhou ZN: Intermittent hypoxia protects the rat heart against ischemia/ reperfusion injury by activating protein kinase c. Life Sci 2004;75:2587-2603.

-39 Iwamoto T, Pan Y, Wakabayashi S, Imagawa T, Yamanaka HI, Shigekawa M: Phosphorylation-dependent regulation of cardiac $\mathrm{Na}^{+} / \mathrm{Ca}^{2+}$ exchanger via protein kinase c. J Biol Chem 1996;271:13609-13615.

-40 Qu Y, Torchia J, Sen AK: Protein kinase c mediated activation and phosphorylation of $\mathrm{Ca}^{2+}$-pump in cardiac sarcolemma. Can J Physiol Pharmacol 1992;70:1230-1235.

-41 Takasago T, Imagawa T, Furukawa K, Ogurusu T, Shigekawa M: Regulation of the cardiac ryanodine receptor by protein kinase-dependent phosphorylation. J Biochem 1991;109:163-170.

42 Coronado R, Morrissette J, Sukhareva M, Vaughan DM: Structure and function of ryanodine receptors. Am J Physiol 1994;266:C1485-1504.

43 Si KW, Liu JT, He LC, Li XK, Gou W, Liu CH, Li XQ: Effects of caulophine on caffeine-induced cellular injury and calcium homeostasis in rat cardiomyocytes. Basic Clin Pharmacol Toxicol 2011;107:976-981.

44 Gyorke S, Terentyev D: Modulation of ryanodine receptor by luminal calcium and accessory proteins in health and cardiac disease. Cardiovasc Res 2008;77:245-255.

-45 Stolen TO, Hoydal MA, Kemi OJ, Catalucci D, Ceci M, Aasum E, Larsen T, Rolim N, Condorelli G, Smith GL, Wisloff $\mathrm{U}$ : Interval training normalizes cardiomyocyte function, diastolic $\mathrm{Ca}^{2+}$ control, and $\mathrm{sr} \mathrm{Ca}^{2+}$ release synchronicity in a mouse model of diabetic cardiomyopathy. Circ Res 2009;105:527-536.

46 Terentyev D, Viatchenko-Karpinski S, Gyorke I, Volpe P, Williams SC, Gyorke S: Calsequestrin determines the functional size and stability of cardiac intracellular calcium stores: Mechanism for hereditary arrhythmia. Proc Natl Acad Sci USA 2003;100:11759-11764.

-47 Song L, Alcalai R, Arad M, Wolf CM, Toka O, Conner DA, Berul CI, Eldar M, Seidman CE, Seidman JG: Calsequestrin 2 (casq2) mutations increase expression of calreticulin and ryanodine receptors, causing catecholaminergic polymorphic ventricular tachycardia. J Clin Invest 2007;117:1814-1823.

-48 D'Souza KM, Ashavaid TF: Caprine cardiac sarcoplasmic reticulum isolation and biochemical characterisation with emphasis on $\mathrm{Ca}^{2+}$-adenosine triphosphatase. Indian J Clin Biochem 2007;22:37-44.

49 Ehler E, Moore-Morris T, Lange S: Isolation and culture of neonatal mouse cardiomyocytes. J Vis Exp 2013;doi: 10.3791/50154.

50 Chlopcikova S, Psotova J, Miketova P: Neonatal rat cardiomyocytes--a model for the study of morphological, biochemical and electrophysiological characteristics of the heart. Biomed Pap Med Fac Univ Palacky Olomouc Czech Repub 2001;145:49-55.

51 Mitcheson JS, Hancox JC, Levi AJ: Cultured adult cardiac myocytes: Future applications, culture methods, morphological and electrophysiological properties. Cardiovasc Res 1998;39:280-300. 